\title{
Efficacy and Safety of the Intraosseous Vascular Access in out- of-Hospital Emergencies: A Prospective Study of the Pre-Hospital Emergency Service (SUEM 118) of Padua from 2012 to Today
}

\author{
Andrea Paoli, Marco Lorenzini", Annalisa Boscolo, Andrea Spagna and Carlo Ori \\ Pre-hospital Emergency Service (SUEM 118), UOC Anesthesia and Intensive Care Unit, Hospital of \\ Padova, Italy
}

*Corresponding author: Marco Lorenzini, MD, Pre-hospital Emergency Service (SUEM 118), UOC Anesthesia and Intensive Care Unit, Hospital of Padova, 2, Giustiniani St., 35128 Padova, Italy

\begin{abstract}
Background: Several scientific associations recommend the use of the intraosseous access as a valid alternative to the intravenous route, which is often difficult to find in emergency conditions, as a safe and effective way for drugs and fluids administration and for blood sampling.

Aim of the study: The purpose of this study was the evaluation of the use of the EZ-IO ${ }^{\circledR}$ device, by the S.U.E.M. 118 of Padua, in terms of efficacy and safety in obtaining intraosseous vascular access for fluids and drugs infusions in an out-of-hospital emergency setting.
\end{abstract}

Materials and methods: From February 2012 to May 2016, all cases of pre-hospital 10 access within the operational areas of the Pre-hospital Emergency Service (SUEM 118) of Padua were prospectively recorded. Data were collected by using a standardized grid and by consulting the online computer server Galileo. Data were then analysed by using the Statgraphics Centurion and Microsoft ${ }^{\circledR}$ Excel software.

Results: 89 patients required an intraosseous vascular access. Needles' placement using the EZ-IO device was successful in $97.75 \%$ (87/89). Considering only first attempts, the success rate is $95.51 \%(85 / 89)$. No immediate complications were observed. After one year, one patient was found to have an abscess at the insertion site, but there are insufficient data to establish the cause. Pain was evaluated in 38 patients, after administration of Lidocaine and the Mean value was calculated to be 3 and standard deviation (sd) 2. Only one patient reported unbearable pain (10/10).

Conclusions: The high percentage of successful insertions along with low complication rates, shows that the use of intraosseous vascular access should be considered as first line treatment in out-of-hospital emergencies, whenever a rapid and safe vascular access is required, thus it can be used in every situation where a vascular access is impossible to obtain, regardless of the clinical conditions of the patient and the elapsed time.

\section{Keywords}

Intraosseous, Vascular, Access, Trauma, EZ-IO, Pre-hospital, Emergency

\section{Introduction}

Rapid intravascular access is of paramount importance in both in and out-of-hospital emergency care. Quick treatment of medical and traumatic situations, along with correct resuscitation maneuvers, can decrease the mortality and morbidity rates of a critical patient [1]. The peripheral venous catheter (IV) represents the actual standard of care, although during cardio-circulatory arrest, shock conditions, sepsis, burns, major trauma and epilepsy, the failure rate was reported to be up to $10-40 \%$ [2-4]. Patients suffering from obesity, edema, dehydrated ones, on chemotherapies, or those who do drugs intravenously, peripheral intravenous access may be difficult to obtain, thus representing a delay that affects the patient's management [5]. The intraosseous vascular access intraosseous (IO) is a valid alternative to parenteral drugs and fluids administration, which is characterized by ease of learning and effectiveness equal to the peripheral catheterization in terms of pharmacokinetics and clinical efficacy [6]. It is

Citation: Paoli A, Lorenzini M, Boscolo A, Spagna A, Ori C (2018) Efficacy and Safety of the Intraosseous Vascular Access in out-of-Hospital Emergencies: A Prospective Study of the Pre-Hospital Emergency Service (SUEM 118) of Padua from 2012 to Today. Int J Anesthetic Anesthesiol 5:082. doi. org/10.23937/2377-4630/1410082

Accepted: December 04, 2018: Published: December 06, 2018

Copyright: (C) 2018 Paoli A, et al. This is an open-access article distributed under the terms of the Creative Commons Attribution License, which permits unrestricted use, distribution, and reproduction in any medium, provided the original author and source are credited. 
a recommended route in both pediatric and adult patients in case of difficult peripheral venous cannulation, because it is safer and quicker to obtain, if compared to the central venous catheter (CVC) in out-of-hospital settings [5].

According to the 2015 update of the European Resuscitation Council guidelines, the 10 access is a rapid, safe and effective way to administer drugs, fluids and blood products [7]. Moreover, "whenever a venous access is difficult or impossible to obtain, the intraosseous access should be considered (IO). Although it is usually considered as an alternative vascular access in children, its use is currently accepted also for adults. The intraosseous injection of drugs allows to reach a suitable concentration of drug in a time which is comparable to the injection through a central venous catheter. The recent availability of mechanical instruments for intraosseous administration has made this technique easier to use".

In fact, as claimed by Drinker [8-10], the bone tissue, beyond its structural, metabolic-hormonal functions and bone marrow reserve, is also a highly-vascularized organ. Subsequent studies [8,9] demonstrated that the intraosseous compartment, within the spongeous portion of both long and flat bones, hides an extremely extensive vascular network which is non-expandable and incompressible. Through the latter, it is possible to administer any drugs, fluids and blood products.

The use of the 10 access as a vascular immediate alternative access to unsuccessful peripheral venous access in emergency conditions was recently introduced in their guidelines by the following societies: American Heart Association (AHA), European Resuscitation Council (ERC), American College of Emergency Physicians (ACEP), American Academy of Pediatrics (AAP), American College of Surgeons (ACS), the American College of Critical Care Medicine (ACCM), the US National Association for Emergency Medical Service Physicians (NAEMSP) and US Army Committee on Tactical Combat Casual Care (TCCC) [11], whose directions are illustrated in Table 1.

According to the ALS protocol, attempts of peripheral cannulation in adult patients should be carried out for more than 120 seconds. Recent studies propose to reduce this time to 90 seconds or, eventually, to proceed with an intraosseous vascular access after 2 failed attempts of peripheral venous cannulation.

The $\mathrm{EZ}-\mathrm{IO}{ }^{\circledR}$ device was approved by the FDA in 2004 for its use both in pediatric patients and adult, which is a battery-powered drill and stainless needles, specifically designed for intravascular access [12] (Figure 1).

\section{Purpose of the Study}

The purpose of this study was the evaluation of the use of the $\mathrm{EZ} \mathrm{IO}^{\circledR}$ device, in terms of efficacy and safety

\section{EZ-IO ${ }^{\circledR}$ Power Driver and Needle Sets: Description}

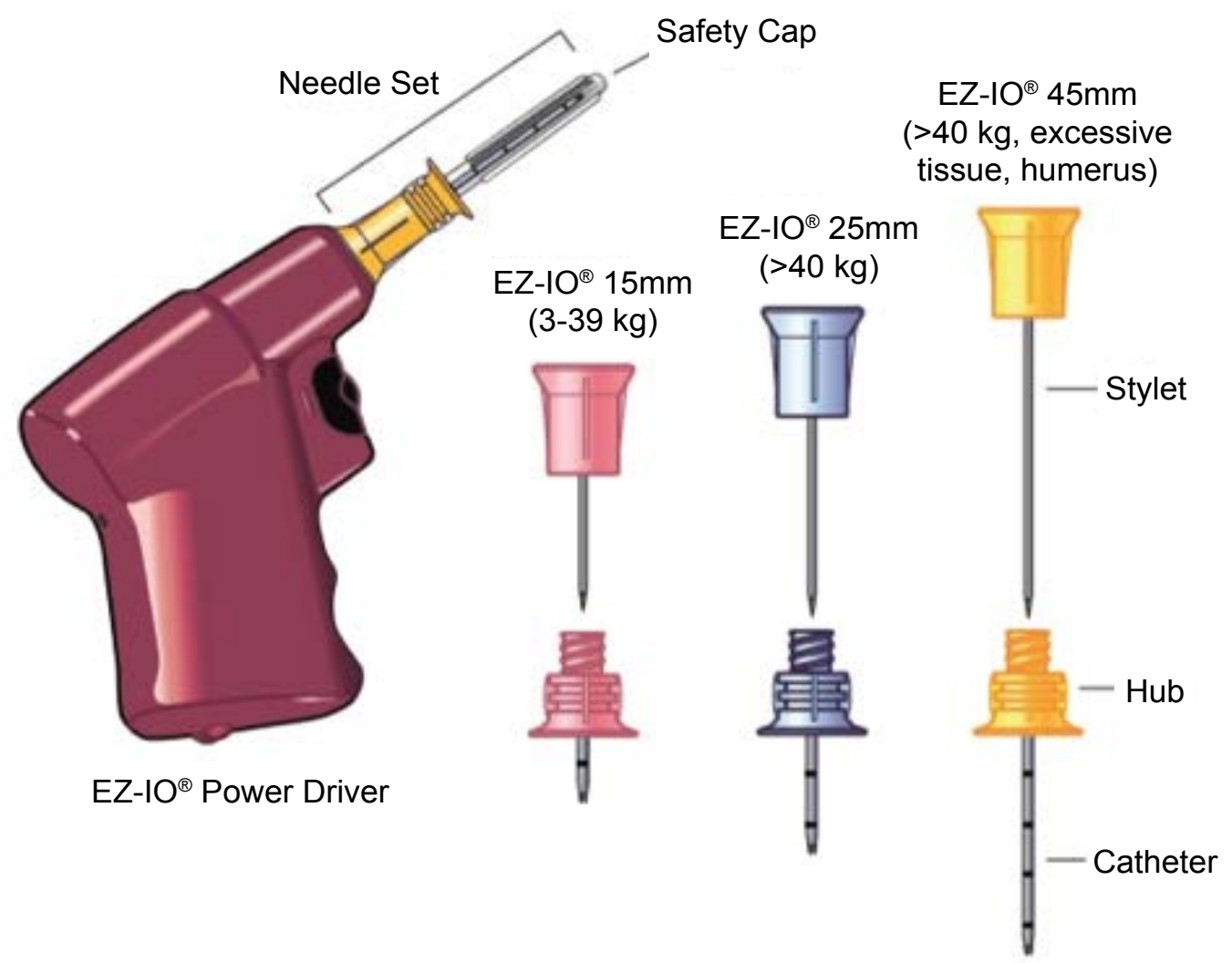

Figure 1: EZ-IO semiautomatic device, equipped with a battery-powered drill and set of needles (15G, 25G, 45G). 
in obtaining an intraosseous vascular access for fluids and drugs infusions in an out-of-hospital emergency setting. The study was performed by the Pre-hospital Emergency Service (SUEM 118) of Padua.

We focused on simplicity of use, effectiveness and pain management. Moreover, immediate complications following intraosseous needle insertion and after one week were also checked. We then compared our data, collected from February 2012 to May 2016, with the data reported in the literature.

\section{Materials and Methods}

This prospective observational study was conducted from February 2012 to May 2016 (52 months), at the Pre-hospital Emergency Service (SUEM 118) of Padua.

\section{The EZ-IO device}

Based on the data in the literature, the medical and nursing staff was trained to use the EZ-IO, a portable battery-powered drill, which was approved by the FDA in 2004. Both medical cars and helicopter of the S.U.E.M. 118 of Padua are equipped with this device.

In 2012, part of the staff took part at a training course in Rotterdam based on intraosseous vascular access management. The participants could then arrange a training session for the entire team of the Pre-hospital Emergency Service (SUEM 118), which lasted 4 hours: one hour lecture and three hours of core training on the

Table 1: Indications for $I O$ access.

\begin{tabular}{|l|l|}
\hline 1 & Sepsis \\
\hline 2 & Therapeutic cooling \\
\hline 3 & Altered level of consciousness \\
\hline 4 & Respiratory arrest \\
\hline 5 & Cardiac arrest \\
\hline 6 & Status epilepticus \\
\hline 7 & Kidney failure \\
\hline 8 & Diabetes \\
\hline 9 & Haemodynamic instability \\
\hline 10 & Shock \\
\hline 11 & Major trauma \\
\hline 12 & hypovolemia \\
\hline 13 & Obesity \\
\hline 14 & Stroke \\
\hline 15 & Overdose \\
\hline 16 & Burns $\left(2^{\circ}{ }^{\circ}\right.$ degree over body surface area $\left.>30 \%\right)$ \\
\hline 17 & Dehydration \\
\hline 18 & Anafilaxis \\
\hline 19 & Cardiac arrhythmias \\
\hline
\end{tabular}

use of the $\mathrm{EZ}-1 \mathrm{O}^{\circledR}$ device using artificial bones, provided directly by the manufacturer.

The criteria used for the positioning of intraosseous vascular access were those outlined in the ERC guidelines, according to which the intraosseous vascular access must be searched when a valid peripheral vascular access cannot be found within 120 seconds or within 60 seconds, in adult or pediatric patient, respectively, along with one or more of the conditions listed in Table 1.

Compared to guidelines, the medical and nursing staff of S.U.E.M. 118 of Padua used the intraosseous route whenever it was necessary to find a vascular access, regardless of the presence or absence of the clinical conditions listed above.

The insertion was considered effective if the needle resulted securely fastened to the bone after insertion and the operator could infuse $10 \mathrm{ml}$ of saline solution without encountering any resistance and extravasation around the needle.

The first phase of the study involved a questionnaire, which was specifically designed for data collection of patients in which the EZ-IO device has been used. The questionnaire was filled in at the end of every intervention.

The total number of procedures performed by the S.U.E.M. 118 of Padua during this study was 16918, 89 of which required the insertion of an intraosseous vascular access.

The questionnaire was completed by the operator who performed the intraosseous access, whereas part of the data relating to remote complications were searched online, via the Galileo program for medical records.

\section{Statistical Analysis of Data}

An electronic database (using Microsoft Access 2007) was created with the collected data, which were then analyzed using the software Statgraphics. Mean, mode and standard deviations were calculated were possible and then used to compere the results. Moreover, the latter were then compared with data from other prospective studies in the literature regarding the use of the intraosseous vascular access.

\section{Results}

The number of interventions carried out with the

Table 2: Interventions performed by the Pre-hospital Emergency Service (SUEM 118) both by medical cars and helicopter, from February 2012 to May 2016.

\begin{tabular}{l} 
Mission Year \\
\hline Medical cars 1-2 \\
\hline Helicopter \\
\hline Total \\
\hline lo Patients \\
\hline Usage percentage \\
\hline
\end{tabular}

\begin{tabular}{|l|l|l|l|l|l|}
\hline 2012 & $\mathbf{2 0 1 3}$ & $\mathbf{2 0 1 4}$ & $\mathbf{2 0 1 5}$ & $\mathbf{2 0 1 6}$ & TOTALE \\
\hline 3583 & $\mathbf{3 5 6 0}$ & $\mathbf{3 5 9 4}$ & $\mathbf{3 6 2 5}$ & $\mathbf{1 4 4 0}$ & $\mathbf{1 5 8 0 2}$ \\
\hline 257 & 224 & 242 & 302 & 91 & $\mathbf{1 1 1 6}$ \\
\hline $\mathbf{3 8 4 0}$ & $\mathbf{3 7 8 4}$ & $\mathbf{3 8 3 6}$ & $\mathbf{3 9 2 7}$ & $\mathbf{1 5 3 1}$ & $\mathbf{1 6 9 1 8}$ \\
\hline 22 & 24 & 14 & 24 & 5 & $\mathbf{8 9}$ \\
\hline $0.57 \%$ & $0.63 \%$ & $0.36 \%$ & $0.61 \%$ & $0.33 \%$ & $\mathbf{0 . 5 3} \%$ \\
\hline
\end{tabular}


two medical cars during this study was 15802, plus 1116 performed by the helicopter, resulting in 16918 interventions from February 2012 to May 2016 (Table 2).

89 patients required an intraosseous vascular access. The total number of accesses taken is 91 , as for 2 patients the access was taken 2 times.

\section{Demographic and clinical data of patients involved in this study (Table 3 )}

Sex or age of 7 out of 89 patients is unknown.

Summary statistics and confidence interval (IC) are shown in Table 4 and Table 5, excluding cardiac arrest.

\section{Success rate and type of intervention}

89 patients required the positioning of an intraosseous vascular access.

Table 3: Breakdown of patients by sex and age.

\begin{tabular}{|l|l|l|l|}
\hline & Male & Female & Overall \\
\hline Adults & 49 & 27 & 76 \\
\hline Children < 15 yo & 3 & 3 & 6 \\
\hline Overall & 52 & 30 & $\mathbf{8 2}$ \\
\hline
\end{tabular}

The percentage of successful intraosseous access using the EZ-IO device was $97.75 \%$ (87/89). Considering the first attempt success, the percentage is $95.51 \%$ (85/89).

For one patient, some difficulties during aspiration were encountered after needle insertion, with subsequent successful repositioning of the needle in the contralateral limb.

In one patient, the needle was first inserted into the soft tissues and then promptly removed and successfully repositioned within the bone by a second operator.

2 cases of needle malfunction were reported, one concerning difficulties during infusion, while, as far as the other is concerned, no pharmacologic effect was observed after administration of drugs through the intraosseous route.

$42 \%$ of intervention, which required the placement of an intraosseous device involved patients in cardiac arrest. $30 \%$ of patients were rescued for traumatic reasons while the remaining $28 \%$ suffered from medical emergencies (Figure 2).

Table 4: Summary Statistics.

\begin{tabular}{|l|l|l|l|l|}
\hline & Systolic Blood Press & Diastolic Blood Press & Heart Rate & SpO $\%$ \\
\hline Overall & 37 & 37 & 37 & 37 \\
\hline Mean & 119.973 & 66.2432 & 91.0811 & 90.1892 \\
\hline Standard deviation & 35.2905 & 23.5719 & 27.8192 & 13.6317 \\
\hline Variation coefficient & $29.4153 \%$ & $35.5838 \%$ & $30.5434 \%$ & $15.1146 \%$ \\
\hline Minimum & 50.0 & 30.0 & 45.0 & 45.0 \\
\hline Maximum & 200.0 & 120.0 & 140.0 & 100.0 \\
\hline Range & 150.0 & 90.0 & 95.0 & 55.0 \\
\hline
\end{tabular}

Table 5: Confidence intervals at 95\%.

\begin{tabular}{|l|l|l|l|l|}
\hline & Mean & Std error & Lower limit & Higher limit \\
\hline Systolic BP max & 119.973 & 5.80171 & 108.207 & 131.739 \\
\hline Diastolic BP min & 66.2432 & 3.87519 & 58.384 & 74.1025 \\
\hline HR & 91.0811 & 4.57345 & 81.8057 & 100.356 \\
\hline SpO $_{2} \%$ & 90.1892 & 2.24104 & 85.6441 & 94.7342 \\
\hline
\end{tabular}

\section{TYPE OF INTERVENTION}

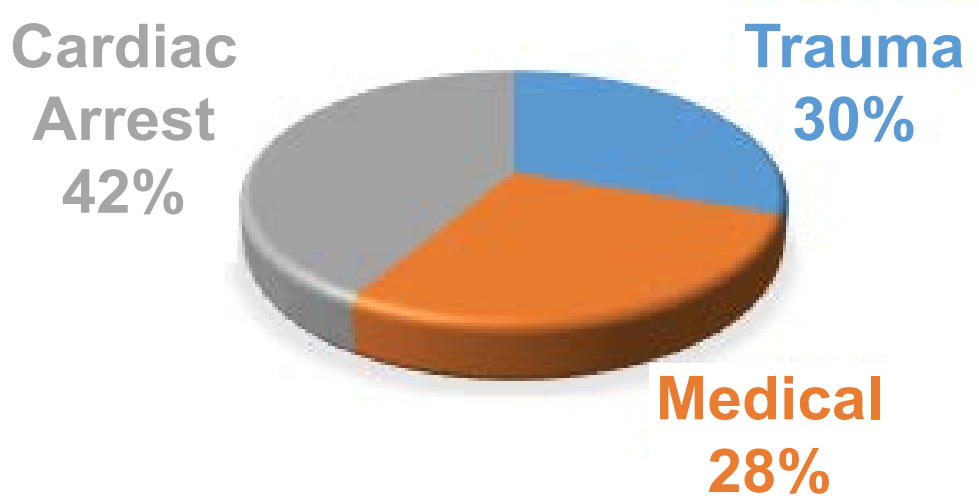

Figure 2: Percentages of intervention of S.U.E.M. 118 of Padua according to type. 


\section{Insertion sites, type of needles and operators}

The number of needles used deviates from the number of patients because in 2 cases (two adult patients) the needle was repositioned (Table 6).

Both fluids and drugs could be administered through the 10 access (Table 7).

\section{Evaluation of correct positioning}

An intraosseous vascular access was considered correctly positioned if no immediate complications, such as edema of the insertion site, difficulties during aspiration or infusion could be observed.

Table 6: Needle insertion site, absolute numbers and percentages.

\begin{tabular}{|l|l|l|}
\hline Site & $\mathbf{N}^{\circ}$ of patients & Use $\%$ \\
\hline Humerus & 10 & $10.99 \%$ \\
\hline Distal Tibia & 2 & $2.20 \%$ \\
\hline Proximal Tibia* & 79 & $86.81 \%$ \\
\hline Overall needles used & 91 & $100.00 \%$ \\
\hline
\end{tabular}

*2 of which are needles used as a second attempt (see previous analysis).

Table 7: Types of drugs and fluids used and their frequency.

\begin{tabular}{|l|l|}
\hline Drug type & $\mathbf{N}^{\circ}$ patients \\
\hline Amine & 44 \\
\hline Analgesics & 25 \\
\hline Curari & 12 \\
\hline Hypnotics/Sedatives & 17 \\
\hline Succinylcholine & 2 \\
\hline Corticosteroids & 1 \\
\hline Antibiotics & 1 \\
\hline Effortil & 4 \\
\hline Amiodarone & 5 \\
\hline Flumazenil and Naloxone & 1 \\
\hline Magnesium Sulfate & 3 \\
\hline Insulin & 1 \\
\hline Atropine & 1 \\
\hline Furosemide & 4 \\
\hline Calcium Chloride & 1 \\
\hline Sodium bicarbonate & 1 \\
\hline Fluids & \\
\hline Physiological Solution & 65 \\
\hline Lactated Ringer & 17 \\
\hline Plasma Expander & 14 \\
\hline ER III & 0 \\
\hline Glucosate & 2 \\
\hline Physiological Solution + Ringer Lactate & 10 \\
\hline Physiological Solution + Ringer Lactate + ER III & 4 \\
\hline & \\
\hline
\end{tabular}

Table 8: Percentages of correct insertion.

\begin{tabular}{|l|l|l|}
\hline Correct Insertion & Insertion Fails & Used Needles \\
\hline 88 & 3 & 91 \\
\hline $96.70 \%$ & $3.30 \%$ & \\
\hline
\end{tabular}

Fluids and drugs administration through an intraosseous vascular access was carried out in 88 placements out of 91 (96.7\%) (Table 8). 85 of the latter were positioned correctly on the first attempt, while 2 were inserted correctly at the second attempt (Table 9). Only once, the doctor, despite a correct needle insertion, did not detect any effect of the drugs administered through the access (Table 10).

In one patient, however, the device did not work, thus it was removed.

The proportion of successfully positioned needles is $95 \%$ with a level $1-\alpha=95 \%$.

\section{Pain management}

The following table and figure show the Perception of pain during the administration of drugs and fluids to patients with GCS $\geq 9$, according to the NRS scale, after administration of lidocaine and its distribution of frequencies (Table 11 and Figure 3).

\section{Immediate complications, after one week and after one year}

No short-term complications were identified, such as extravasation, compartment syndrome or fractures, the latter mainly related to the use of a semi-automatic device. For 3 out of 89 patients (3.37\%) difficulties were reported, concerning infusion, which were mostly related to a wrong positioning of the device.

As far as long term complications are concerned, only 38 patients could be studied because:

- 33 patients died on the spot.

- 2 patients died upon arrival at the emergency room.

Table 10: Percentages of incorrect insertion, divided by attempts.

\begin{tabular}{|l|l|l|l|}
\hline $\begin{array}{l}\text { Incorrect } \\
\text { insertion }\end{array}$ & First attempt & Malfunctioning & Total fails \\
\hline & 2 & 1 & 3 \\
\hline$\%$ MARGINAL & $66.67 \%$ & $33.33 \%$ & \\
\hline$\%$ TOTAL & $2.20 \%$ & $1.10 \%$ & \\
\hline
\end{tabular}

Table 11: Perception of pain during the administration of drugs and fluids to patients with GCS $\geq 9$, according to the NRS scale, after administration of lidocaine.

\begin{tabular}{|l|l|}
\hline NRS Value Scale & $\mathbf{N}^{\circ}$ of patients \\
\hline 0 & 5 \\
\hline 2 & 1 \\
\hline 3 & 19 \\
\hline 4 & 9 \\
\hline 5 & 3 \\
\hline 10 & 1 \\
\hline
\end{tabular}

Table 9: Percentages of correct insertion, divided by attempts.

\begin{tabular}{|l|l|l|l|l|l|}
\hline Correct insertion & First Attempt & Second Attempt & First Attempt but no pharmacological effect & Total Success \\
\hline & 85 & 2 & 1 & 88 \\
\hline \% MARGINAL & $96.59 \%$ & $2.27 \%$ & $1.14 \%$ & \\
\hline \% TOTAL & $93.41 \%$ & $2.20 \%$ & $1.10 \%$ & \\
\hline
\end{tabular}




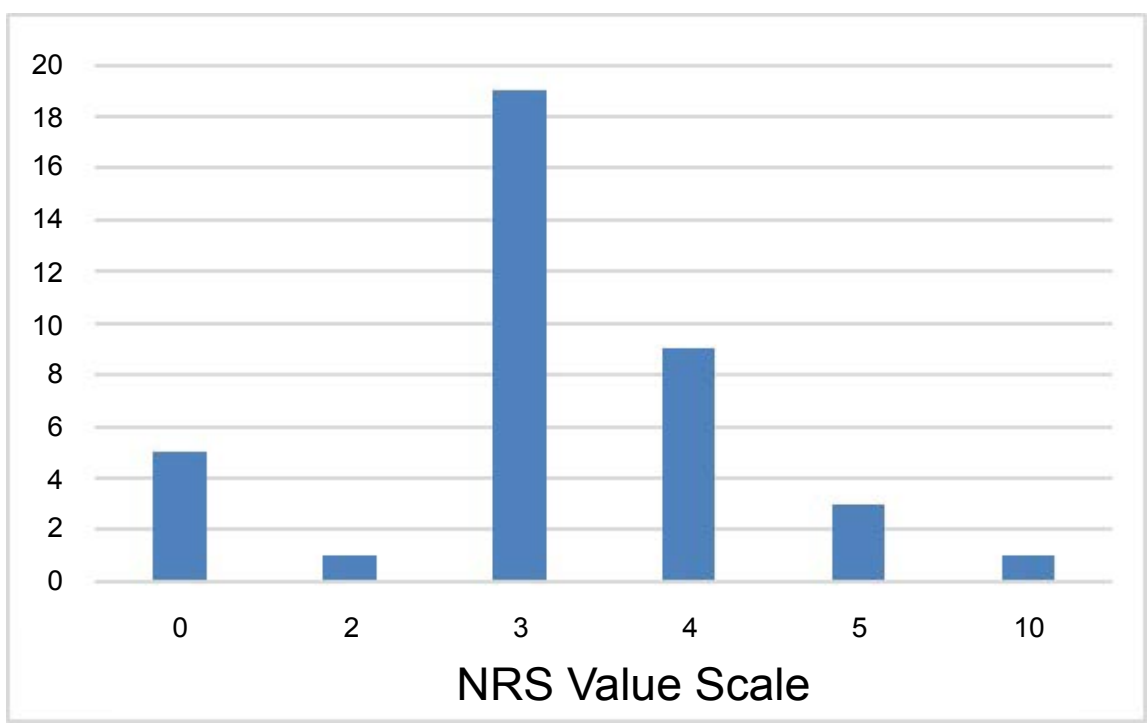

Figure 3: Distribution of frequencies of the NRS scale value.

Table 12: Comparison of the success rates reported in the literature and percentages of this study.

\begin{tabular}{|l|l|l|l|l|l|}
\hline Author & Year & IO suitable patients & Interventions & Use\% & Study length \\
\hline Gazin, et al. [13] & 2010 & 39 & 9876 & $0.39 \%$ & 1 year \\
\hline Schalk, et al. [14] & 2011 & 74 & 18615 & $0.40 \%$ & 2 years \\
\hline Santos [15] & 2012 & 58 & 8378 & $0.69 \%$ & 2 years \\
\hline This study (Padova) & 2016 & 89 & 16918 & $0.53 \%$ & 5 years \\
\hline
\end{tabular}

- 4 patients died within 7 days from the date of intervention.

- 12 patients moved to different facilities than the Clinical University Hospital of Padua and ULSS 16 Ospedale Sant'Antonio, thus no follow up could be performed.

\section{CVC/CVP placement}

In 46 out of 89 patients (51.68\%) a peripheral venous catheter could be placed, 3 of which were positioned in the out-of-hospital setting by the staff of Pre-hospital Emergency Service (SUEM 118) of Padua. Due to poor venous heritage, 8 of these patients $(17.39 \%)$ required a central venous catheter (CVC) upon arrival at the emergency room, whereas for 2 patients $(4.35 \%)$ both types catheters were positioned.

Out of the 43 remaining patients, who were not suitable for a peripheral vascular access, 29 died, whereas 10 could not be assessed either due to lack of information or because they were transferred to other facilities. Finally, in 4 patients it was impossible to find a peripheral vascular access due to anatomical difficulties.

\section{Discussion}

The results of this study demonstrate the efficacy and the safety of the intraosseous vascular access in the management of the out-of-hospital emergency, according to data collected by the Pre-hospital Emergency Service (SUEM 118) team of Padua.

The period of this study goes from February 2012 to May 2016 (52 months), during which 16,918 interventions were performed, 89 of which required the use of an intraosseous vascular access, thus the $0.53 \%$. In fact, this value deviates from those obtained in other studies in the literature (Table 12); considering the study by Gazin, et al. [13]. in 2010, the percentage of intraosseous vascular access was of $0.39 \%$. The following year, similar values were also obtained by Schalk, et al. [14] (0.40\%), whereas, in Switzerland, the study conducted by Santos [15] in 2012 reported a much greater frequency of intraosseous device use, equal to $0.69 \%$.

These differences follow multiple explanations. The three studies differ, in the first place, for their duration: in fact, the one conducted in Padua is the longest (five years), if compared to the other three. Other critical points are the different area of expertise and the different annual number of calls each emergency Care Unit receives. As far as Padua is concerned, the S.U.E.M. 118 is equipped with 2 medical cars and a helicopter, both active $24 / 7$ but only in case of emergency. Medical cars serve the territory of ULSS 16 Padua, excluding the territory of Piove di Sacco and neighboring municipalities, which are managed by Piove di Sacco, with a total population of 367,731 inhabitants (as of 2010). The helicopter rescue service, on the other hand, covers the entire Veneto region and there are 4 bases (Padua, Verona, Treviso and Pieve di Cadore). These settings are very similar to those of Santos [15], whereas in the studies by Gazin [13] and Schalk [14] the Emergency Care Units covered an area of over a million citizens. Another explanation for these different percentages can be related to the fact that, in the other three studies, the intraos- 
Table 13: Missions carried out by the S.U.E.M. 118 of Padua in the study period and rates of use of the intraosseous access.

\begin{tabular}{|l|l|l|l|l|l|l|}
\hline Mission (Year) & $\mathbf{2 0 1 2}$ & $\mathbf{2 0 1 3}$ & $\mathbf{2 0 1 4}$ & $\mathbf{2 0 1 5}$ & $\mathbf{2 0 1 6}$ & Total \\
\hline Total & $\mathbf{3 8 4 0}$ & $\mathbf{3 7 8 4}$ & $\mathbf{3 8 3 6}$ & $\mathbf{3 9 2 7}$ & $\mathbf{1 5 3 1}$ & $\mathbf{1 6 9 1 8}$ \\
\hline lo patients & 22 & 24 & 14 & 24 & 5 & $\mathbf{8 9}$ \\
\hline Use percentage & $0.57 \%$ & $0.63 \%$ & $0.36 \%$ & $0.61 \%$ & $0.33 \%$ & $\mathbf{0 . 5 3 \%}$ \\
\hline
\end{tabular}

seous access could be performed not only by the doctor or nurse but also by paramedics. $0.53 \%$ was calculated on the total number of operations performed in the 52 months of observation, in fact, from an annual analysis of the number of $\mathrm{IO}$ accesses taken, the percentages are fluctuating (Table 13).

In 2013 and 2015 the proportion of patients suitable for the intraosseous access was similar to that reported by Santos, whereas, in 2014 its use was lower, as there were only 14 interventions out of 3836 which required an intraosseous access. If compared to the study conducted by Schalk [14], the percentage turns out to be greater, also due to the smaller number of interventions carried out (16918 interventions in Padua in 5 years against 18615 interventions in 2 years). In addition, we considered only major interventions, which required the presence of the physician and the nurse on the field. Minor interventions, which represent most the incoming calls to 118 , are dealt by volunteers, which are not allowed to place any vascular access. Therefore, if all incoming calls had been included in the study, the percentage would have been even lower. Moreover, not every request for major intervention required an emergency treatment, thus there was no urge to place a vascular access as quickly as possible. Finally, the intraosseous vascular access is still a secondchoice treatment, according to the current guidelines, compared to the peripheral one. We must underline that, the high training level of the Emergency Care crew in obtaining a peripheral access might have contributed to opt for the latter, which remains the actual standard of care. Objectively, the use of the intraosseous access by the medical and nursing staff, during the study, of the Emergency Unit has allowed us to establish that such a technique is to be used whenever a vascular access is needed, and we are not able to get it, regardless of the clinical condition of the patient and the number of attempts made.

An international review of the literature states the IO route is very underutilized compared to its potential because CVC is preferred as second and third choice [16]. About this, Hallas, et al. [17] created a questionnaire, which ended with the question "Have you ever been in a clinical situation, where an intraosseous vascular access would have been useful, but you did not use it? If so, why?" and it was given to the members of the Danish Society for Emergency Medicine (Dasein). 700 doctors and 53 nurses and paramedics took part at the study. $23.5 \%$ of the respondents happened to be in that situation. The lack 10 devices followed by a lack of information and theoretical and practical training to the use of this technique are the main reasons they did not opt for the intraosseous access. Some of them did not even know it existed. A more recent study, conducted in Varsavia [18], on a group of 60 newly qualified doctors confirms what Hallas highlighted six years ago; In fact, only $6.7 \%$ of respondents said they received specific training for the 10 during this study, while $100 \%$ of the new doctors stated that the use of the intraosseous device should be an essential part of the medical background of every doctor. Before the advent of the semi-automatic EZ-IO device, the Prehospital Emergency Service of Padua was equipped with the Jamshidi needle, which was more difficult to use, especially in adult patients, but also had a greater risk of micro-fractures at the insertion site and other possible complications. Unfortunately, there are no previous studies conducted by the S.U.E.M. 118 of Padua about this manual needle, but doctors and nurses, who participated in this study, reported that the semi-automatic $\mathrm{EZ}-\mathrm{IO}^{\circledR}$ was easier to use than Jamshidi.

\section{Patient characteristics}

The predominance of males in our sample of study is in line with the literature and is probably due to the greater number of traumatic and cardiovascular events, compared with those of medical nature.

The medical emergencies, which led to the positioning of an 10 vascular access, was $25 \%$, whereas $30 \%$ of its use can be related to traumatic events.

The highest percentage of use of the $\mathrm{EZ}-1 \mathrm{IO}^{\circledR}$ device is during the cardiovascular arrests (42\%), data comparable with the literature, as stated in the studies by Gazin, et al. [13]., Santos, et al. and Schalk, et al. [14,15], who also reported in their groups a predominance of this type of events.

This is because the use of intraosseous vascular access was included in the AHA and ERC guidelines for the management of cardiovascular events first (2005), and only three years later the American College of Surgeons Committee on Trauma recommended its use for trauma as well. The endotracheal route, which was used in trauma only, it was abandoned in 2010, recommending the use of $\mathrm{IO}$ access for any resuscitation conditions.

\section{Ease of use}

The number of correct placements by using the EZ$10^{\circledR}$ device was 88 out of 91 (96.7\%), thus very much alike what stated in the literature, as shown in Table 14.

2 out of 3 cases of incorrect placement were 
Table 14: Comparison of the success rates and the sample size of the studies in the literature with the following Thesis.

\begin{tabular}{|l|l|l|l|}
\hline Publication & Type of study & Sample size & Success (\%) \\
\hline Torres, et al. [34] & Observational prospective & 107 (114 IO) & $100(114)$ \\
\hline Tan, et al. [35] & Observational prospective & 42 & $93(39)$ \\
\hline Leidel, et al. [5] & Controlled randomized & 40 (B.I.G. + EZ-IO) & $85(34)$ \\
\hline Myers, et al. [36] & Retrospective & $60(62$ IO) & $87(54)$ \\
\hline Schalk, et al. [14] & Observational prospective & 77 & $97(75)$ \\
\hline Gazin, et al. [13] & Observational prospective & 39 & $85(33)$ \\
\hline Reades, et al. [37] & Observational prospective & 88 & $69(61)$ \\
\hline Sunde, et al. [31] & Retrospective & 49 & $96(47)$ \\
\hline Paxton, et al. [4] & Observational prospective & 30 & $97(29)$ \\
\hline Frascone, et al. [38] & Observational prospective & 19 & $95(18)$ \\
\hline Ong, et al. [39] & Observational prospective & 35 & $100(35)$ \\
\hline Horton, et al. [40] & Observational prospective & 95 & $94(89)$ \\
\hline Frascone, et al. [41] & Observational prospective & 89 & $88(78)$ \\
\hline Davidoff, et al. [19] & Observational prospective & 250 & $97(242)$ \\
\hline Gillum, et al. [42] & Observational prospective & 125 & $94(118)$ \\
\hline Santos, et al. [15] & Observational prospective & $58(60$ IO) & $90(54)$ \\
\hline Studio Padova & Observational prospective & $\mathbf{8 9 ( 9 1 ~ I O )}$ & $96.7(88)$ \\
\hline
\end{tabular}

repositioned by another operator with a positive result, while the third one was removed by the operator because of malfunctioning.

The marginal rate of success in the first attempt is $96.59 \%(85 / 88)$, while the total percentage of success is $93.41 \%$ (85/91). The percentage increases to $98.86 \%$ and $95.61 \%$, respectively, marginal one and total one, if one includes the 10 accesses successfully inserted with a second attempt.

Obesity delayed the localization of reference points on two occasions, making the needle insertion more difficult: difficulty during aspiration was observed in one case, which resulted in the removal of 10 access and its repositioning by a second operator in the contralateral limb successfully. In the second patient, the intraosseous needle was placed in the soft tissues but promptly and properly relocated by another operator in the proximal tibia. In one case, the 10 access could not be used because of resistance during aspiration.

Due to the small size of this sample, it is not possible to establish if there are any differences between the positioning by medical personnel rather than nurses. A review of the literature shows that 10 access is performed by doctors in most of the EU countries, whereas in American studies, nurses and paramedical staff are those who mainly use the device. Studies on larger samples (247 patients), however, demonstrated a success rate at the first attempt of $91 \%$, which increases to $94 \%$ if second attempt successes are included [19].

The intraosseous vascular access is more reliable and faster to obtain than peripheral or central catheters, thus the delay in the execution of resuscitation maneuvers and transfer of the patient to the hospital decrease, improving the patient's outcome $[5,20]$. Back in 2006, Minville showed in his study that, in emergency conditions, the percentage of success at the first attempt in obtaining a peripheral vascular access can reduce to $76 \%$ [21]. Muir, et al. [22] proved that, although the infusion time through the 10 access is significantly higher than the IV route, the IO access is quicker to obtain, thereby it nullifies the advantage of IV route on the 10 one.

Although several studies revealed a lower rate of correct insertion at the first attempt of humeral 10 access than tibial, Johnson, et al. [23] showed that 10 humeral access has a greater infusion flow $(213 \mathrm{~mL} /$ $\mathrm{min}$ ) compared to the tibial $(103 \mathrm{~mL} / \mathrm{min})$, therefore, it turns out to be the most appropriate site to be used in case of cardiopulmonary resuscitation. Moreover, Douma proved the that it is possible to place 2 humeral IO accesses simultaneously, with no complications, increasing greatly the flow of infusion [24].

In terms of pharmacokinetics, there is a statistically significant difference in Maximum Concentration (Cmax) obtainable using the sternal IO compared to IV route, as well as between the IO tibial route and the IV access [25]. In his study, Burgert [25] demonstrates that the serum concentration of $1 \mathrm{mg}$ of epinephrine administered via IV is 5.87 and 2.86 times greater than the serum concentration detected after tibial and sternal 10 administration respectively. Statistically significant differences also exist concerning the maximum time (Tmax) required to reach these concentrations between the use of the tibial IO access and the IV route, as well as between the tibial IO and the sternal IO access, where IO tibial requires longer time 87. On the other hand, there are no statistically significant differences in Tmax between the intravenous route and the sternal 10 access [25].

Animal studies suggest that the Cmax of adrenaline is reached more quickly when administered intravenously than through the intraosseous route, even if the sternal IO way has a very close pharmacokinetics to the IV access.

Proximal tibia was the most used insertion site 
(91.82\%), similarly to different studies in the literature, according to which the tibial 10 access has a higher rate of success in the first attempt and It is the fastest site for a vascular access to be obtained during Cardiovascular Arrest, if compared to humeral 10 and peripheral venous catheterization. In 2015, during the National Congress of the Italian Resuscitation Council in Parma the new 2015 CPR guidelines proved the IO access to be just as much important as the IV access. In trauma management, the literature confirms that the 10 access can be used to quickly administer life-saving drugs in a simple and complication-free way, thus it can be considered an alternative way of obtaining a vascular access. This turns out to be of vital importance during resuscitation of a traumatized patient.

Obesity was the major obstacle in this study, because of difficulties in locating the landmarks, thus in positioning the device. To shorten the time of placement of a vascular access in patients with $\mathrm{BMI}>30 \mathrm{~kg} / \mathrm{m}^{2}$ practical training of the personnel could be improved. As well, proper training material for obese patients could be asked to be provided by the manufacturer.

\section{Effectiveness of the device}

For one patient, despite a correct insertion of the intraosseous device, no pharmacological effect could be detected after administration of drugs. The insertion was correct because no limb edema after administration of $10 \mathrm{ml}$ of saline was observed. We were not able to explain this finding because studies on pharmacokinetics show clinical significant differences in 74 serum levels of drugs administered by intraosseous and IV ways only in case of certain antibiotics, such as ceftriaxone, chloramphenicol, phenytoin, tobramycin, and vancomycin. No response at all was reported only in two pediatric patients with supraventricular 24-26 tachycardia after injection of adenosine.

The results of our study proved the device to be an excellent tool not only for out-of-hospital emergencies. In fact, in one case the intraosseous access, which was positioned in the extra-hospital setting, was effectively used by the anesthetist in the operating room to induce anesthesia. In another patient, the IO access was used by the emergency room doctor to administer Pantorc and Ketorolac, given the difficulties they encounter on finding a valid peripheral access.

The present study also showed that the intraosseous vascular route can be used to provide adequate fluid resuscitation, in fact in 46 out of 89 patients (51.68\%) a peripheral venous access could be found. For three of these patients the catheters were placed by same rescuers.

\section{Complication rating}

No short-term complications such as extravasation or compartment syndrome could be observed, despite
Table 15: Comparison between the error percentages reported in the literature with the present study.

\begin{tabular}{|l|l|l|}
\hline Publication & \% Complication & No. of patients \\
\hline Torres, et al. [34] & 0 & 114 \\
\hline Leidel, et al. [5] & 0 & 34 \\
\hline Myers, et al. [36] & 0 & 54 \\
\hline Gazin, et al. [13] & 0 & 33 \\
\hline Reades, et al. [37] & 0 & 61 \\
\hline Sunde, et al. [31] & 4 & 47 \\
\hline Frascone, et al. [38] & 26 & 18 \\
\hline Ong, et al. [39] & 0 & 35 \\
\hline Horton, et al. [40] & 0 & 89 \\
\hline Davidoff, et al. [19] & 0.8 & 242 \\
\hline Gillum, et al. [42] & 0 & 125 \\
\hline Santos, et al. [15] & 0 & 58 \\
\hline Padova 2013 & $\mathbf{3 . 2}$ & $\mathbf{3 1}$ \\
\hline This study (Padova) 2016 & $\mathbf{1 . 1 2}$ & $\mathbf{8 9}$ \\
\hline
\end{tabular}

the use of a semi-automatic device. For only 3 out of 89 patients (3.37\%) infusion difficulties could be reported, but mainly related to a wrong positioning of the device. None of these patients manifested any complications later.

One-week-complications could be assessed in 38 patients only, but none emerged from our survey data. For one patient only the ER report shows the presence of an abscess, one year after, where the intraosseous needle was originally inserted. No additional data are available at the moment. Due to the lack of information, it is not possible to establish if this incident might be a consequence of the intraosseous vascular access.

Considering both immediate and one-week complications, the percentage is $1.12 \%(1 / 89)$, as shown in Table 15.

The detected percentage of complications is $1.12 \%$, data that is comparable in terms of sample size and percentage of complications to most prospective observational studies in the literature. Compared to a previous study conducted here in Padova in 2003 (31 patients), where the complication rate was $3.2 \%$, this decrement is likely to be a consequence of a greater sample size, but mostly because of an improvement and refinement of the ability to obtain 10 vascular accesses.

\section{Pain management}

Most rescued patients were in cardiac arrest. A studio [26], which dates to 2013, proposed the following clinical scenario: "You are rescuing a patient in overdosed with GCS 6, who needs an intraosseous vascular access. Your colleague tells you that pre-infusion of lidocaine before fluids administration is unnecessary. Is there any evidence about that?" There are no case-control studies in the literature regarding the efficacy of lidocaine in relieving pain during intraosseous infusion, but there are studies that show that increasing doses of lidocaine in fact reduce the perceived pain, consequently it has some effect [26]. 
Pain during the 10 infusion is a consequence of the rapid increase of the intramedullary pressure. Within these non-expandable cavities there are numerous pain receptors. However, there are few studies in the literature that deal with the management of pain during infusion.

As far as insertion pain is concerned, three studies describe it using the VAS score (1-10) with an average of 3.7 [27-29]. 5 studies on the level of pain perceived during infusion, which also used the VAS score (1-10), reported an average value of 5.4 [19,27-29].

In this study, according to Italian Society of Anesthesia, Analgesia, Resuscitation and Intensive Care (SIAARTI) guidelines on emergency pain management, we assessed pain during needle insertion and during infusion in $38 \mathrm{pa}-$ tients, excluding those in cardiac arrest or unconscious.

The medical and nursing staff involved in the project were trained to administer anesthetics in all conscious patients before starting the infusion of fluids and medications.

All conscious patients were treated with $40 \mathrm{mg}$ of lidocaine pre-infusion and $50 \%$ of them still experienced a pain level of 3. Only one patient experienced a pain level of 10 on the NRS scale, that required the removal of needle. Finally, 5 patients did not experience any pain.

Pain management is still a challenge. Similarly, in a study conducted by Schalk [14], 18 out of 22 conscious patients experienced pain, although no quantification scales were used. $29.7 \%$ of the participants complained about pain, more during infusion rather than during needle insertion. For only one patient infusion had to be stopped because too painful, thus a central venous catheter was inserted. $20-40 \mathrm{mg}$ Lidocaine was administered in 4 out of 22 patients who did not complained any discomfort and in 8 out of 18 patients with pain.

The data obtained by Cooper, et al. [30] are also very interesting, concerning the insertion of 32 intraosseous vascular access using the EZ-IO device in the military field: all conscious patients experienced pain and for 3 patients it was even stronger than wounds caused by the fighting.

The Pre-hospital Emergency Service (SUEM 118) of Padua decided to adopt the Vidacare pain management procedure, as recommended by Dr. Richard Hixson (Figure 4).

However, where appropriate and under prescription of the physician, analgesia was obtained by intranasal, transoral or 10 administration of Fentanyl, or by using ketamine.

\section{Intraosseous administration of preservative-free lidocaine Read this guideline fully before use - if in doubt seek senior medical advice}

Patient with intraosseous (10) needle in situ and responsive to pain.

Aspirate marrow for laboratory analysis, cross-match and culture if required.

Exclude contra-indications to lidocaine:

Sino-atrial disorders, all grades of AV block, severe myocardial depression, acute porphyria.

Consider cautions to lidocaine:

Epilepsy, respiratory impairment, impaired cardiac function, bradycardia, severe shock, myasthenia gravis, hepatic and renal impairment, congestive cardiac failure, hypertension, elderly, post-op cardiac surgical patients, reduce dose in debilitated patients.

Monitor patient clinically. Consider additional monitoring as indicated.

Administer initial (higher) dose of 10 lidocaine over 1 to 2 minutes.
Flush the 10 needle with up to $10 \mathrm{ml}$ sodium chloride $0.9 \%$ over 5 seconds. "

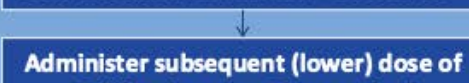
IO lidocaine over 30 seconds. *

Inject or infuse fluids and medication under pressure as required. *

If discomfort re-occurs, consider repeating the subsequent (lower) dose of $\mathrm{IO}$ lidocaine at a maximum frequency of once every 45 minutes. *

* Observe for extravasation, hypersensitivity and other side-effects with every 10 lidocaine injection:

Dizziness, parasthesia, nystagmus, rash drowsiness, confusion, convulsions, respiratory depression, bradycardia, hypotension, methaemaglobinaemia.

If extravasation occurs, site a new 10 needle. If side effects occur immediately stop administration and treat as appropriate.

* The internal volume of the 10 needle and extension set must be considered when calculating administration speed. Ensure the 10 needle and other 'dead-space' has been totally cleared of lidocaine before flush, medication or fluids are commenced.

\begin{tabular}{|c|c|c|c|c|c|}
\hline \multicolumn{6}{|c|}{ Volume of preservative-free lidocaine - titrate 10 to analgesic effect } \\
\hline \multirow[t]{2}{*}{ Age } & \multirow[t]{2}{*}{$\begin{array}{l}\text { Weight } \\
\text { (kg) }\end{array}$} & \multicolumn{2}{|c|}{$\begin{array}{l}\text { Volume of } 2 \%(\mathrm{ml}) \\
1 \mathrm{ml} \text { of } 2 \%=20 \mathrm{mg} / \mathrm{ml}\end{array}$} & \multicolumn{2}{|c|}{$\begin{array}{l}\text { Volume of } 1 \%(\mathrm{ml}) \\
1 \mathrm{ml} \text { of } 1 \%=10 \mathrm{mg} / \mathrm{ml}\end{array}$} \\
\hline & & Initial & Subsequent & Intitial & Subsequent \\
\hline Neonate & 3 & 0.07 & 0.03 & 0.15 & 0.07 \\
\hline Neonate & 4 & 0.1 & 0.05 & 0.2 & 0.1 \\
\hline 7 weeks & 5 & 0.12 & 0.06 & 0.25 & 0.12 \\
\hline 3 months & 6 & 0.15 & 0.07 & 0.3 & 0.15 \\
\hline 5 months & 7 & 0.17 & 0.08 & 0.35 & 0.17 \\
\hline 7 months & 8 & 0.2 & 0.1 & 0.4 & 0.2 \\
\hline 1 year & 9 & 0.22 & 0.11 & 0.45 & 0.22 \\
\hline 15 months & 10 & 0.25 & 0.12 & 0.5 & 0.25 \\
\hline 2 years & 12 & 0.3 & 0.15 & 0.6 & 0.3 \\
\hline 3 years & 14 & 0.35 & 0.17 & 0.7 & 0.35 \\
\hline 4 years & 16 & 0.4 & 0.2 & 0.8 & 0.4 \\
\hline 5 years & 18 & 0.45 & 0.22 & 0.9 & 0.45 \\
\hline 6 years & 20 & 0.5 & 0.25 & 1 & 0.5 \\
\hline 7 years & 23 & 0.57 & 0.28 & 1.1 & 0.57 \\
\hline 8 vears & 26 & 0.65 & 0.32 & 1.3 & 0.65 \\
\hline 9 years & 29 & 0.72 & 0.36 & 1.4 & 0.72 \\
\hline 10 years & 32 & 0.8 & 0.4 & 16 & 0.8 \\
\hline 11 years & 35 & 0.87 & 0.43 & 1.7 & 0.87 \\
\hline 12 vears & 39 & 0.97 & 0.48 & 1.9 & 0.97 \\
\hline 13 years & 44 & 1.1 & 0.55 & 22 & 1.1 \\
\hline 14 years & 50 & 1.2 & 0.62 & 25 & 1.2 \\
\hline 15 years & 54 & 1.3 & 0.67 & 2.6 & 1.3 \\
\hline 16 years & 58 & 1.4 & 0.72 & 28 & 1.4 \\
\hline \multirow{3}{*}{ Aduit } & 60 & 1.5 & 0.75 & 3 & 1.5 \\
\hline & 70 & 1.7 & 0.87 & 3.4 & 1.7 \\
\hline & $80+$ & 2 & 1 & 4 & 2 \\
\hline \multirow{4}{*}{\multicolumn{4}{|c|}{$\begin{array}{l}\text { The lower volumes of } 2 \% \text { lidocaine }(k 1 \mathrm{ml}) \text { may be } \\
\text { difficult to accurately measure and use of , or dilition } \\
\text { to, } 1 \% \text { lidocaine should be considered under these } \\
\text { circumstances. Use the appropriate syringe size for } \\
\text { the volume to administer to ensure maximum } \\
\text { accuracy: }\end{array}$}} & Volume & Syringesize \\
\hline & & & & $0-1 \mathrm{ml}$ & $1 \mathrm{ml}$ \\
\hline & & & & $1-2.5 \mathrm{ml}$ & $2.5 \mathrm{ml}$ \\
\hline & & & & $2.5 .5 \mathrm{ml}$ & $5 \mathrm{ml}$ \\
\hline
\end{tabular}

Figure 4: Richard Hixon's protocol for administration of preservative-free lidocaine. 


\section{Conclusions}

The EZ-IO device should be considered as first choice, in the field of extra-hospital emergencies, when a rapid and safe vascular access is needed. This is supported by the positive trend we observed in our study and by the high percentage of correct insertion and low complication rate. We proved it to be an excellent tool in the extra-hospital setting, but which can also be used by medical and nursing staff during intra-hospital emergencies, whenever a peripheral vascular access cannot be found, both for drug administration and induction of anesthesia.

The device is easy to use as proved by the staff of the Pre-hospital Emergency Service of Padua, who could manage it properly after only four hours training and one hour frontal lecture, followed by practical exercises on mannequins and fresh eggs.

The medical and nursing staff, in this study, show the efficacy, effectiveness and safety of this technique to quickly locate a valid vascular access. The latter turned out to be of vital importance for prompt administration of fluids and drugs, not only in patients with any of the clinical conditions indicated in the ERC guidelines. In fact, the 10 access was used in all those situations where a vascular access could not be found, regardless of the clinical condition of the patient, the elapsed time and the number of attempts.
As further proof of our 5 years of practical experience on the field using the intraosseous vascular access, last February 2016 the Advanced Simulation Unit organized the course "Alternative vascular access to intravenous: intraosseous and intranasal" (Figure 5). The course, as part of the simulARTi project of the Anesthesiology and Intensive Care unit, directed by Professor Carlo Ori of the Department of Medicine, University of Padua, is divided into lectures, with advanced electronic simulators and practical exercises during a cadaver session. The aim of the course is to give theoretical and practical notions concerning the management of intraosseous and intranasal accesses.

Intranasal and transoral routes are of vital importance for drugs administration in emergency conditions, because of their advantageous pharmacokinetics. In fact, in particular circumstances, they are still preferred over the IO. For example, during pain management, we must not ignore the SIAARTI guidelines, according to which the type of analgesic and the route of administration should be selected based on an adequate pain assessment. Considering the environmental and clinical conditions the medical and nursing staff of S.U.E.M. 118 of Padua faces every day, 10 administration, although safe and effective, is not always the most suitable way for obtaining the desired therapeutic effect.

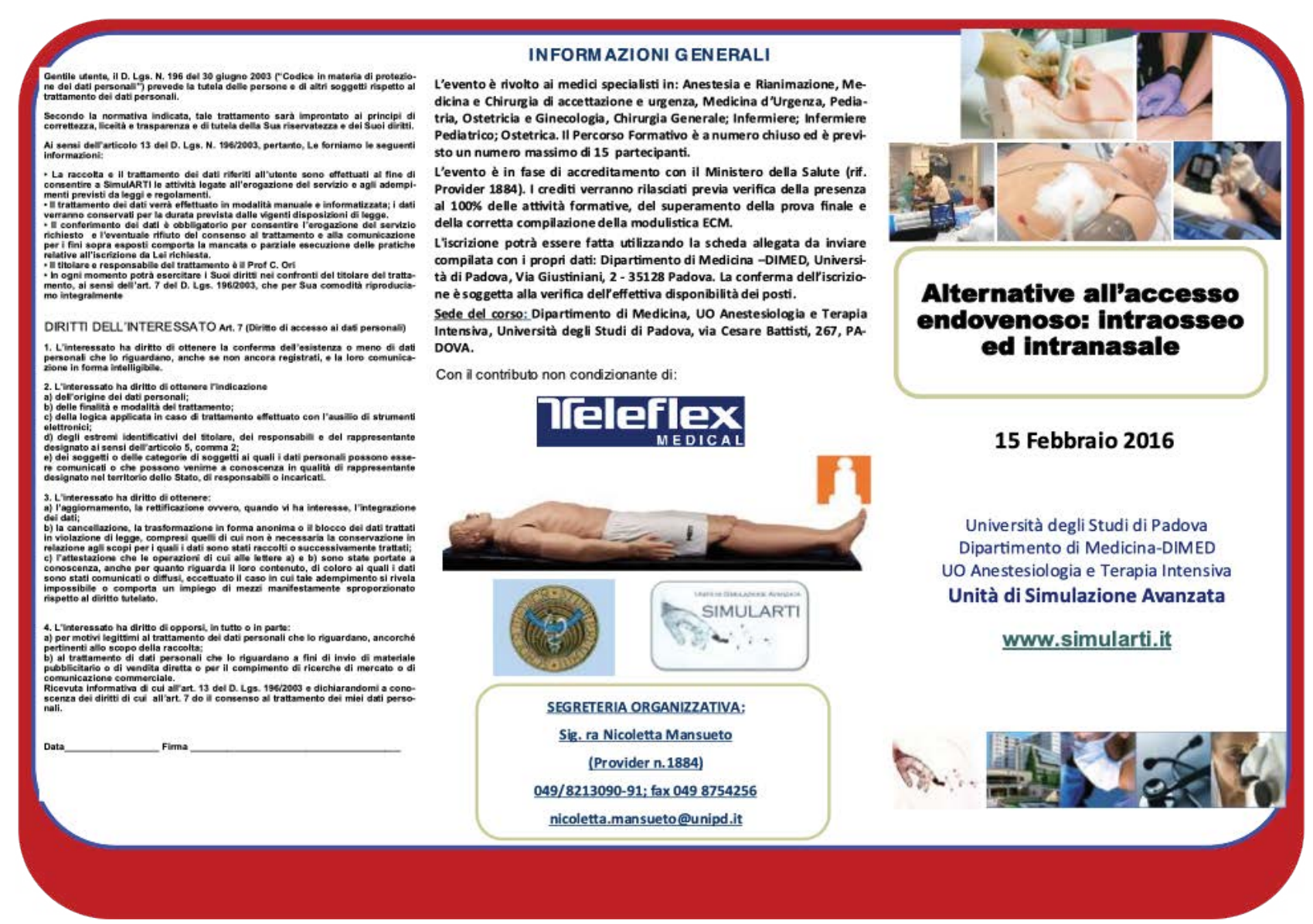

Figure 5: Alternative vascular access to intravenous: intraosseous and intranasal. simulARTi project of the Anesthesiology and Intensive Care unit, directed by Professor Carlo Ori of the Department of Medicine, University of Padua. 


\section{References}

1. Voigt J, Waltzman M, Lottenberg L (2012) Intraosseous vascular access for in-hospital emergency use: A systematic clinical review of the literature and analysis. Pediatr Emerg Care 28: 185-199.

2. Costantino TG, Parikh AK, Satz WA, Fojtik JP (2005) Ultrasonography-guided peripheral intravenous access versus traditional approaches in patients with difficult intravenous access. Ann Emerg Med 46: 456-461.

3. Lapostolle F, Catineau J, Garrigue B, Monmarteau V, Houssaye T, et al. (2007) Prospective evaluation of peripheral venous access difficulty in emergency care. Intensive Care Med 33: 1452-1457.

4. Paxton JH, Knuth TE, Klausner HA (2009) Proximal humerus intraosseous infusion: A preferred emergency venous access. J Trauma 67: 606-611.

5. Leidel BA, Kirchhoff C, Bogner V, Braunstein V, Biberthaler $P$, et al. (2012) Comparison of intraosseous versus central venous vascular access in adults under resuscitation in the emergency department with inaccessible peripheral veins. Resuscitation 83: 40-45.

6. Neuhaus D (2014) Intraosseous infusion in elective and emergency pediatric anesthesia: When should we use it? Curr Opin Anaesthesiol 27: 282-287.

7. Soar J, Nolan JP, Böttiger BW, Perkins GD, Lott C, et al (2015) European Resuscitation Council Guidelines for Resuscitation 2015: Section 3. Adult advanced life support. Resuscitation 95: 100-147.

8. Drinker C, Drinker K, Lund C (1922) The circulation of the mammalian bone marrow. Am J Physiol 62: 1-92.

9. Tocantis LO, JF (1945) Complications of intraosseous therapy. Ann Surg 122: 266-277.

10. Doan C (1922) The circulation of the bone marrow. Contrib Embryol 12: 27

11. Luck RP, Haines C, Mull CC (2010) Intraosseous access. J Emerg Med 39: 468-475.

12. Calkins MD, Fitzgerald G, Bentley TB, Burris D (2000) Intraosseous infusion devices: A comparison for potential use in special operations. J Trauma 48: 1068-1074.

13. Gazin N, Auger H, Jabre P, Jaulin C, Lecarpentier E, et al. (2011) Efficacy and safety of the EZ-IO intraosseous device: Out-of-hospital implementation of a management algorithm for difficult vascular access. Resuscitation 82: 126-129.

14. Schalk R, Schweigkofler U, Lotz G, Zacharowski K, Latasch L, et al. (2011) Efficacy of the EZ-IO needle driver for out-ofhospital intraosseous access--a preliminary, observational, multicenter study. Scand J Trauma Resusc Emerg Med 19: 65.

15. Santos D, Carron PN, Yersin B, Pasquier M (2013) EZ$\mathrm{IO}((\mathrm{R}))$ intraosseous device implementation in a prehospital emergency service: A prospective study and review of the literature. Resuscitation 84: 440-445.

16. (1997) American Academy of Pediatrics \& American Heart Association. Vascular access, textbook of pediatric life support, Lippincott \& Wilkins.

17. Hallas P, Brabrand M, Folkestad L (2012) Reasons for not using intraosseous access in critical illness. Emerg Med $\mathrm{J}$ 29: $506-507$

18. Szarpak L, Kurowski A, Adamczyk P, Czyzewski L, Truszewski Z, et al. (2016) Are junior doctors trained to use to use intraosseous access? Am J Emerg Med 34: 107.
19. Davidoff J, Fowler R, Gordon D, Klein G, Kovar J, et al. (2005) Clinical evaluation of a novel intraosseous device for adults: Prospective, 250-patient, multi-center trial. JEMS 30: 20-23.

20. Banerjee S, Singhi SC, Singh S, Singh M (1994) The intraosseous route is a suitable alternative to intravenous route for fluid resuscitation in severely dehydrated children. Indian Pediatr 31: 1511-1520.

21. Minville V, Pianezza A, Asehnoune K, Cabardis S, Smail N (2006) Prehospital intravenous line placement assessment in the French emergency system: A prospective study. Eur J Anaesthesiol 23: 594-597.

22. Muir SL, Sheppard LB, Maika-Wilson A (2016) A comparison of the effects of intraosseous and intravenous $5 \%$ albumin on infusion time and hemodynamic measures in a swine model of hemorrhagic shock. Prehosp Disaster Med 31: 436-442.

23. Johnson D, Garcia-Blanco J, Burgert J, Fulton L, Kadilak $P$, et al. (2015) Effects of humeral intraosseous versus intravenous epinephrine on pharmacokinetics and return of spontaneous circulation in a porcine cardiac arrest model: A randomized control trial. Ann Med Surg (Lond) 4: 306310.

24. Douma MJ, Bara GS, O'Dochartaigh D, Brindley PG (2015) Double-barrelled resuscitation: $A$ feasibility and simulation study of dual-intraosseous needles into a single humerus. Injury 46: 2239-2242.

25. Burgert J, Gegel B, Loughren M, Ceremuga T, Desai M, et al. (2012) Comparison of tibial intraosseous, sternal intraosseous, and intravenous routes of administration on pharmacokinetics of epinephrine during cardiac arrest: A pilot study. AANA J 80: S6-S10.

26. Foex B (2013) Towards evidence-based emergency medicine: Best BETs from the manchester royal infirmary. Emerg Med J 30: 423-424.

27. Fowler RL, Pierce A, Nazeer S, TE Philbeck, LJ Miller (2008) 1.199 case series: Powered intraosseous insertion providers safe and effective vascular access for emergency patient. Annals of Emergency Medicine 52: 152.

28. Philbeck TE, Miller L, Montez D (2009) Pain management during intraosseous infusion through the proximal humerus, Annals of Emergency Medicine 54: 128.

29. Miller L, Philbeck T, Montez D, Puga T (2010) Volunteer studies of pain management during intraosseous infusion. Annals of Emergency Medicine 56: 141.

30. Cooper BR, Mahoney PF, Hodgetts TJ, Mellor A (2007) Intra-osseous access (EZ-IO) for resuscitation: UK military combat experience. J R Army Med Corps 153: 314-316.

31. Sunde GA, Heradstveit BE, Vikenes BH, Heltne JK (2010) Emergency intraosseous access in a helicopter emergency medical service: A retrospective study. Scand J Trauma Resusc Emerg Med 18: 52.

32. Shavit I, Hoffmann Y, Galbraith R, Waisman Y (2009) Comparison of two mechanical intraosseous infusion devices: A pilot, randomized crossover trial. Resuscitation 80: 1029-1033.

33. Bukoski A, Winter M, Bandt C, Wilson M, Shih A (2010) Comparison of three intraosseous access techniques in cats. J Vet Emerg Crit Care (San Antonio) 20: 393-397.

34. Torres F, Galan MD, Alonso Mdel M, Suarez R, Camacho C, et al. (2013) Intraosseous access EZ-IO in a prehospital emergency service. J Emerg Nurs 39: 511-514. 
35. Tan BK, Chong S, Koh ZX, Ong ME (2012) EZ-IO in the ED: An observational, prospective study comparing flow rates with proximal and distal tibia intraosseous access in adults. Am J Emerg Med 30: 1602-1606.

36. Myers LA, Russi CS, Arteaga GM (2011) Semiautomatic intraosseous devices in pediatric prehospital care. Prehosp Emerg Care 15: 473-476.

37. Reades R, Studnek JR, Garrett JS, Vandeventer S, Blackwell $T$ (2011) Comparison of first-attempt success between tibial and humeral intraosseous insertions during out-of-hospital cardiac arrest. Prehosp Emerg Care 15: 278-281.

38. Frascone RJ, Jensen J, Wewerka SS, Salzman JG (2009) Use of the pediatric EZ-IO needle by emergency medical services providers. Pediatr Emerg Care 25: 329-332.
39. Ong M, Chan Y, Oh J, Ngo A (2009) An observational, prospective study comparing tibial and humeral intraosseous access using the EZ-IO. Am J Emerg Med 27: 8-15.

40. Horton MA, Beamer C (2008) Powered intraosseous insertion provides safe and effective vascular access for pediatric emergency patients. Pediatr Emerg Care 24: 347350.

41. Frascone RJ, Jensen JP, Kaye K, Salzman JG (2007) Consecutive field trials using two different intraosseous devices. Prehosp Emerg Care 11: 164-171.

42. Gillum L, Kovar J (2005) Powered intraosseous access in the prehospital setting: MCHD EMS puts the EZ-IO to the test. JEMS 30: 24-25. 